\title{
Downregulation of HCN1 Channels in Hippocampus and Prefrontal Cortex in Methamphetamine Re-Exposed Mice With Enhanced Working Memory
}

\author{
Mei ZHOU ${ }^{1}$, Kuan LIN ${ }^{1}$, Yuanren $\mathrm{SI}^{2}$, Qin RU ${ }^{1}$, Lin CHEN ${ }^{1}$, Huaqiao XIAO ${ }^{2}$, Chaoying LI ${ }^{1}$ \\ ${ }^{1}$ Wuhan Institutes of Biomedical Sciences, Jianghan University, Wuhan, China, ${ }^{2}$ Wan Ji Psychiatric \\ Hospital, Wuhan, China
}

Received January 26, 2018

Accepted August 16, 2018

Epub Ahead of Print October 23, 2018

\section{Summary}

The hyperpolarization-activated cyclic-nucleotide-gated non-selective cation ( $\mathrm{HCN}$ ) channels play a potential role in the neurological basis underlying drug addiction. However, little is known about the role of $\mathrm{HCN}$ channels in methamphetamine (METH) abuse. In the present study, we examined the changes in working memory functions of METH re-exposed mice through Morris water maze test, and investigated the protein expression of HCN1 channels and potential mechanisms underlying the modulation of $\mathrm{HCN}$ channels by Western blotting analysis. Mice were injected with METH ( $1 \mathrm{mg} / \mathrm{kg}$, i.p.) once per day for 6 consecutive days. After 5 days without METH, mice were re-exposed to METH at the same concentration. We found that METH re-exposure caused an enhancement of working memory, and a decrease in the HCN1 channels protein expression in both hippocampus and prefrontal cortex. The phosphorylated extracellular regulated protein kinase $1 / 2$ (p-ERK1/2), an important regulator of $\mathrm{HCN}$ channels, was also obviously reduced in hippocampus and prefrontal cortex of mice with METH re-exposure. Meanwhile, acute METH exposure did not affect the working memory function and the protein expressions of HCN1 channels and p-ERK1/2. Overall, our data firstly showed the aberrant protein expression of HCN1 channels in METH re-exposed mice with enhanced working memory, which was probably related to the down-regulation of $\mathrm{p}$-ERK $1 / 2$ protein expression.

\section{Key words}

Methamphetamine - Working memory - HCN channels • Hippocampus • Prefrontal cortex

\section{Corresponding author}

C. Li, Wuhan Institutes of Biomedical Sciences, Jianghan University, Wuhan, 430056, China. Fax: +86-27-84225827. E-mail: licy.whibs.corresp@outlook.com

\section{Introduction}

Methamphetamine (METH) is a worldwide abused psychostimulant with a strong action on the central nervous system. The neuropsychological consequences of METH abuse are memory abnormalities. Precious studies found that low-dose METH could facilitate the memory performance (Schutova et al. 2009, Mahoney et al. 2011, Braren et al. 2014, Rau et al. 2014). However, the molecular mechanism underlying memory enhancement caused by METH treatment is still unclear. Studies suggested that the pathological enhancement of cognitive functions might promote the formation of druginduced associative memory, which was the probable cause of long-lasting addictive behaviors (Hyman 2005). Therefore, researches on the intrinsic mechanism underlying METH-induced memory processes were quite valuable.

The hyperpolarization-activated cyclicnucleotide-gated non-selective cation (HCN) channels underlying $I_{h}$ belong to the superfamily of voltage-gated pore loop channels, which are activated by the membrane hyperpolarization and permeable to $\mathrm{Na}^{+}$and $\mathrm{K}^{+}$. In mammals, HCN channel families compose of 4 members (HCN1-4) that are widely expressed in heart and nervous system. HCN channels exhibited various physiological 
roles, such as the regulator of synaptic plasticity and neurotransmitter release, which played a critical role in the neurological basis underlying memory function (Biel et al. 2009, Benarroch 2013). Recent studies suggested the potential role of $\mathrm{HCN}$ channels in drug addiction. Acute ethanol administration could enhance the $\mathrm{I}_{\mathrm{h}}$ current (Okamoto et al. 2006). Also, a decrease in the $\mathrm{I}_{\mathrm{h}}$ of dopamine neurons in ventral tegmental area (VTA) was observed after a 7-day withdrawal from repeated ethanol administration (Hopf et al. 2007). Cocaine sensitization induced a $40 \%$ decrease in the $\mathrm{I}_{\mathrm{h}}$ amplitude and $45 \%$ reduction in the number of HCN channels in VTA (Arencibia-Albite et al. 2012). However, the role of HCN channels in METH abuse is still unclear.

There was a consensus that $\mathrm{HCN} 1$ channels were the most abundant subunits in hippocampus (HIP) and prefrontal cortex (PFC), which were known to be critical areas associated with memory functions and drug addiction (Notomi and Shigemoto 2004). Relapse was a major characteristic of addictive behavior, and the prevention of relapse was the maintenance strategy for treating addictive behavior. Even after a long period of withdrawal, patients were more likely to be re-exposed to drugs, leading to relapse behaviors (Hendershot et al. 2011). Based on these findings, the present study was aimed to determine whether the protein expression of HCN1 channels was altered in HIP and PFC of mice re-exposed to METH and to investigate the potential mechanism underlying the modulation of $\mathrm{HCN}$ channels protein expression.

\section{Methods}

Animals

Male C57BL/6 mice (20-25 g, 8 weeks) were obtained from the Laboratory Animal Center (Beijing, china). There were 56 mice used in this study. Mice were housed five per cage with a $12 \mathrm{~h}$ light/dark cycle, temperature-controlled environment, and free access to water and food. All animal use procedures were carried out in accordance with the Regulations of Experimental Animal Administration issued by the State Committee of Science and Technology of the People's Republic of China, with the approval of the Ethics Committee in our university.

\section{Animals treatment}

To investigate the effect of METH re-exposure on working memory, animals were randomly divided into two groups: saline group and METH re-exposure group, 11 mice in each group. According to the references (Cao et al. 2013, Macuchova et al. 2013), the dose $1 \mathrm{mg} / \mathrm{kg}$ of METH was chosen. Mice in METH re-exposure group were injected with METH $(0.1 \mathrm{mg} / \mathrm{ml}$, i.p. Hubei Public Security Bureau, China) once per day for 6 consecutive days. After 5 days without METH, mice in METH re-exposure group were re-exposed to METH at the same concentration. Mice in the saline group were injected with isovolumetric saline.

To investigate the effect of acute METH exposure on working memory, animals were randomly divided into two groups: saline group and acute METH exposure group, 11 mice in each group. In the locomotor activity test, different animals were used, 6 mice in each group. Mice in acute METH exposure group were injected with METH ( $1 \mathrm{mg} / \mathrm{kg}, 0.1 \mathrm{mg} / \mathrm{ml}$, i.p. once) one hour before the behavioral testing. Mice in the saline group were injected with isovolumetric saline.

The experimental procedure was detailed in Fig. 1. According to the reference (Cao et al. 2013), all behavioral tests were performed one hour after the injection to avoid the effect of acute METH treatment on the locomotion of mice.

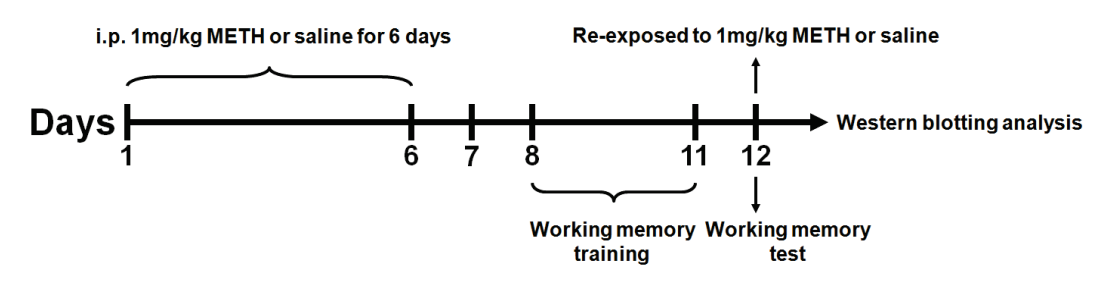

Fig. 1. Experimental procedure.

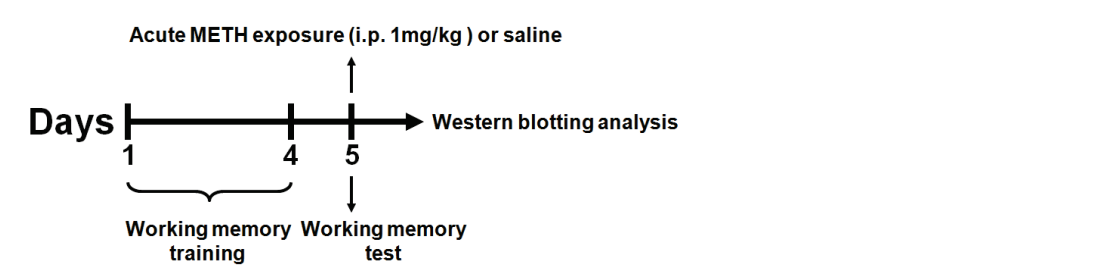




\section{Testing working memory in Morris water maze}

\section{Apparatus}

Briefly, a round pool $(120 \mathrm{~cm}$ diameter, $50 \mathrm{~cm}$ deep) was filled with water at $23 \pm 2{ }^{\circ} \mathrm{C}$ and a depth of $21 \mathrm{~cm}$. A hidden circular platform $(6 \mathrm{~cm}$ diameter $)$ was located $1.5 \mathrm{~cm}$ below the water. Mice were videotaped with the Morris water maze tracking system XR-XM101 (Shanghai Xinruan Informatlon Technology Co. Ltd, China).

\section{Working memory experiment}

Working memory experiment was carried out as previously described by Bigdeli (Miladi Gorji et al. 2008) with slight modification. During the working memory training, mice were trained twice daily with two different starting positions for four consecutive days. In each trial, mice were given up to $60 \mathrm{~s}$ to find the platform. After landing on the platform, mice remained there for $20 \mathrm{~s}$. Mice were guided to the platform and remained there for $20 \mathrm{~s}$ if they failed to find it within $60 \mathrm{~s}$.

Twenty four hours after the final training, working memory tests were performed. In the first trial (acquisition), mice had to find the platform in a new position and remained there for $20 \mathrm{~s}$. One hour after the first trial, mice started from a different point with the same platform position (retrieval). The time spent to find the platform was measured as the escape latency. The shorter the escape latency, the stronger the memory function.

\section{Locomotor activity experiment}

The experimental apparatus consisted of a Plexiglas chamber $(100 \times 100 \times 40 \mathrm{~cm})$ with black grid floor. Mice were injected with saline or METH (1 mg/kg, i.p.), and the locomotor activity was measured $1 \mathrm{~h}$ later in locomotor chamber. The speed and total distance of mice movements during $10 \mathrm{~min}$ period were recorded by a computer-based image analyzer, in order to investigate the effect of METH exposure on the locomotion of mice.

\section{Western blotting analysis}

Brains were quickly removed immediately after the last working memory test (retrieval). HIP and PFC tissues were dissected in cold artificial cerebrospinal fluid. These tissues were homogenized in a protein extraction buffer containing protease and phosphatase inhibitors. Protein concentration was measured using a Protein Assay kit (Boster, China). Proteins were separated on $10 \%$ SDS-PAGE gels and transferred to PVDF membranes (Merck Millipore). After being blocked in $5 \%$ milk for $1 \mathrm{~h}$ at room temperature, membranes were incubated overnight at $4{ }^{\circ} \mathrm{C}$ with the following primary antibodies: anti-HCN1 (1:1,000, NBP1-20250, Novus), anti-p44/42 MAPK (Erk1/2) (1:1,000, 4695S, Cell Signaling), antiphospho-p44/42 MAPK (Thr202/Tyr204) (1:1,000, 9101S, Cell Signaling), or GAPDH (1:5,000, cw0100, Cwbiotech). After incubation with horseradish peroxidase conjugated secondary antibodies (1:5,000; Proteintech Group Inc., China), bands were developed with chemiluminescent substrate (WBKLS0500, Millipore). Immunoreactive signals were quantified by NIH ImageJ software.

\section{Statistical analysis}

Data were presented as mean \pm SEM and analyzed with Independent-Samples Student's t-test. Some data about the swimming speed and escape latency during the learning process in Figure 2 were tested by one-way ANOVA with repeated measures. $\mathrm{P}<0.05$ were considered statistically significant.

\section{Results}

Working memory processes in mice with METH re-exposure

Compared with the saline group, the escape latency was significantly decreased in mice with METH re-exposure on day 4 during the learning process (Fig. $2 \mathrm{~B}, \mathrm{n}=11, \mathrm{P}<0.05$ ), while no significant difference in the swimming speed was observed (Fig. 2A, $\mathrm{P}>0.05$ ). The escape latency was significantly decreased in mice with METH re-exposure in contrast to the saline group in the acquisition trial (Fig. $2 \mathrm{C}-\mathrm{D}, \mathrm{n}=11, \mathrm{P}<0.05$ ), while the escape latency in the retrieval trial exhibited no significant difference (Fig. 2E-F, $\mathrm{P}>0.05$ ). Swimming speeds in the acquisition trial and retrieval trial also exhibited no significant difference between the saline group and METH re-exposure group (Fig. 2G-H, $\mathrm{P}>0.05)$. These findings indicated that $\mathrm{METH}$ re-exposure could enhance the acquisition of working memory. 

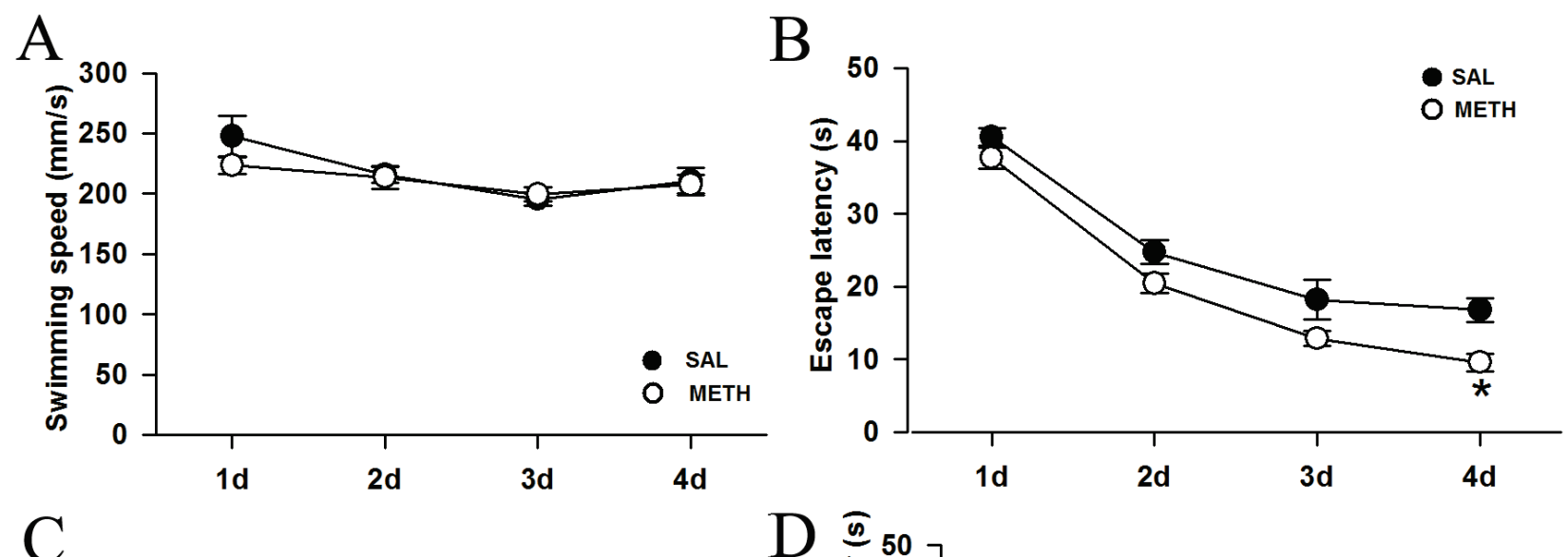

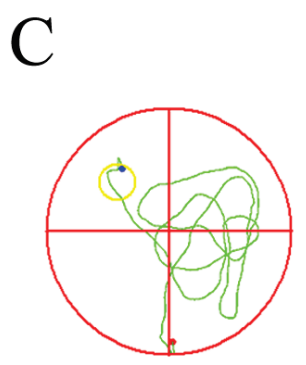

SAL

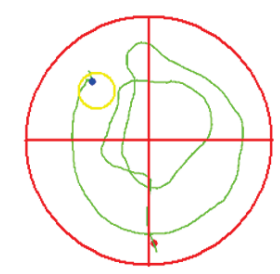

METH

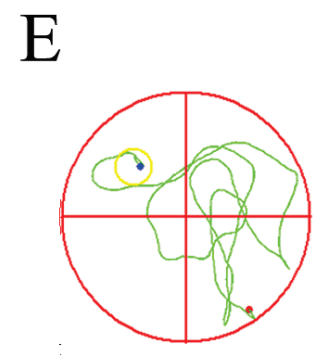

SAL

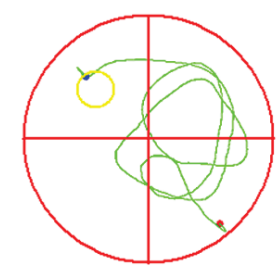

METH

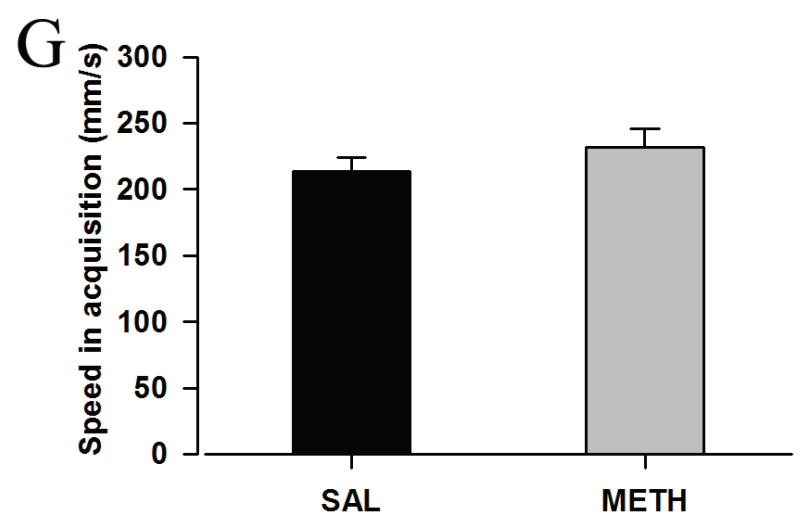

$\mathrm{D}$

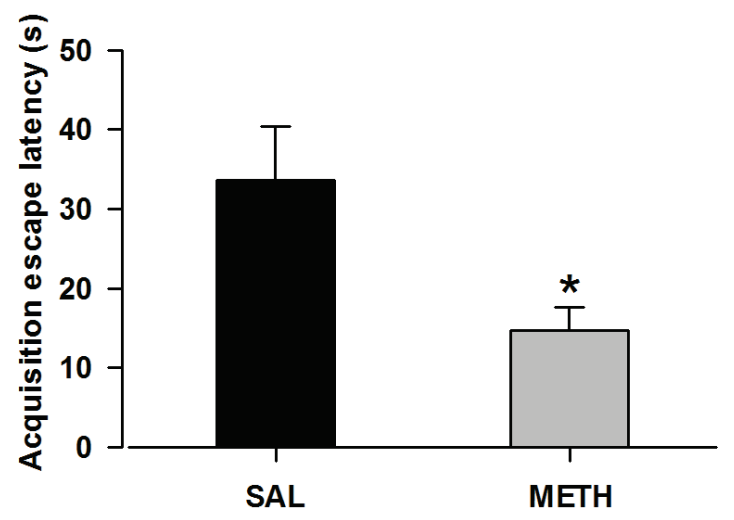

$\mathrm{F}$

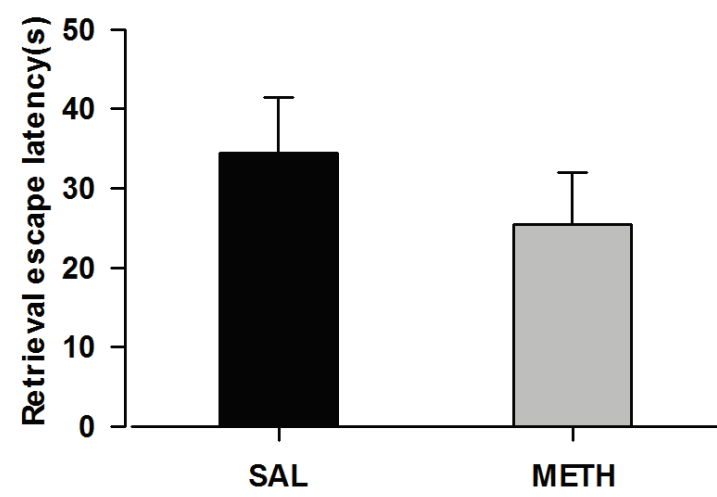

$\mathrm{H}$

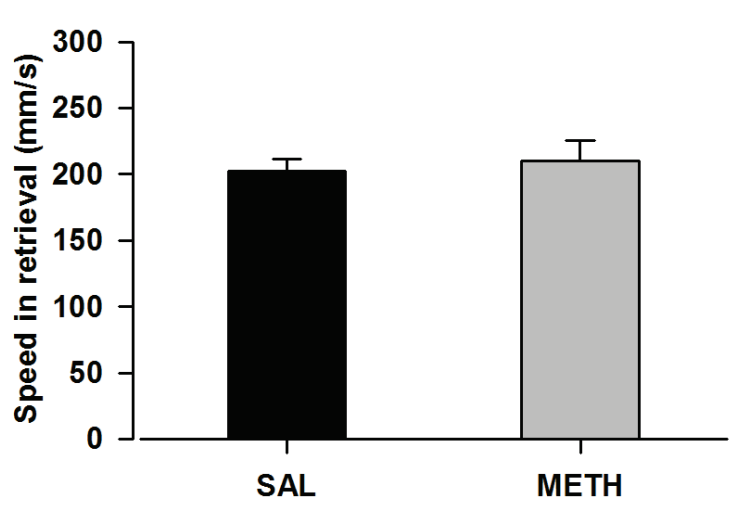

Fig. 2. Effects of METH re-exposure on working memory processes in mice. (A) Swimming speeds during the learning process. No difference was observed between the saline group and METH re-exposure group. (B). The escape latency during the learning process. The escape latency was significantly decreased in mice with METH re-exposure on day 4 during the learning process. (C) Swimming trajectories of acquisition working memory on the test day. (D). The escape latency to find the hidden platform of acquisition working memory on the test day. METH re-exposure significantly reduced the escape latency during acquisition working memory. (E) Swimming trajectories of retrieval working memory on the test day. (F) The escape latency to find the hidden platform of retrieval working memory on the test day. No difference in the retrieval escape latency was observed between the saline group and METH re-exposure group. (G-H) Speeds in acquisition and retrieval working memory. No difference was observed between saline group and METH re-exposure group. $\mathrm{n}=11$ for per group, $* \mathrm{P}<0.05$ vs. saline group. 
Working memory processes in mice with acute METH exposure

No change in escape latencies in the acquisition trial and retrieval trial was observed between the saline group and acute METH exposure group (Fig. 3A-B, $\mathrm{n}=11, \mathrm{P}>0.05)$. Swimming speeds in the acquisition trial and retrieval trial also showed no significant difference between the saline group and acute METH exposure group (Fig. 3C-D, P>0.05). These findings indicated that acute METH exposure did not affect the acquisition of working memory.

Locomotor activity in mice with acute METH exposure

As shown in Figure 4A, one hour after the acute METH exposure, the speed in two groups exhibited no significant differences $(n=6, P>0.05)$. Meanwhile, the total distance of movements in two groups exhibited no significant differences (Fig. 4B, P>0.05), which suggested that acute METH exposure did not affect the locomotion of mice.
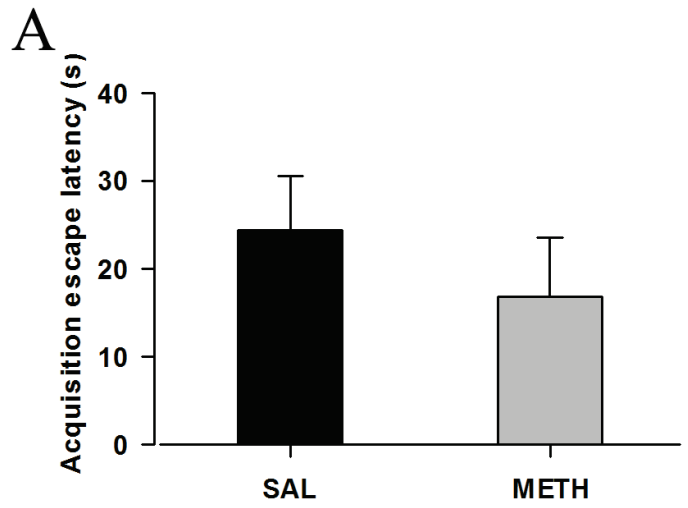

$\mathrm{B}$

\section{$\mathrm{C}$}

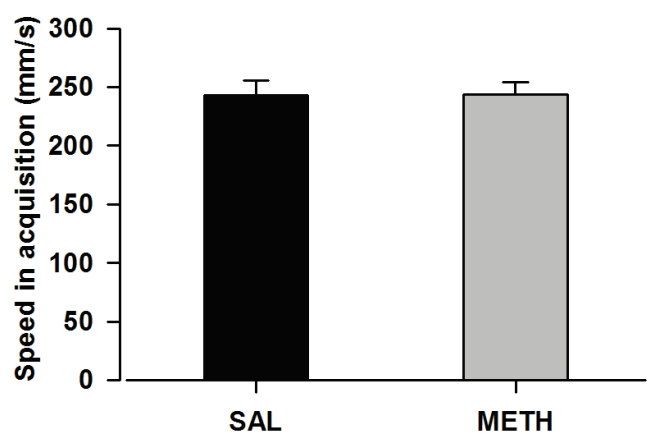

$\mathrm{D}$

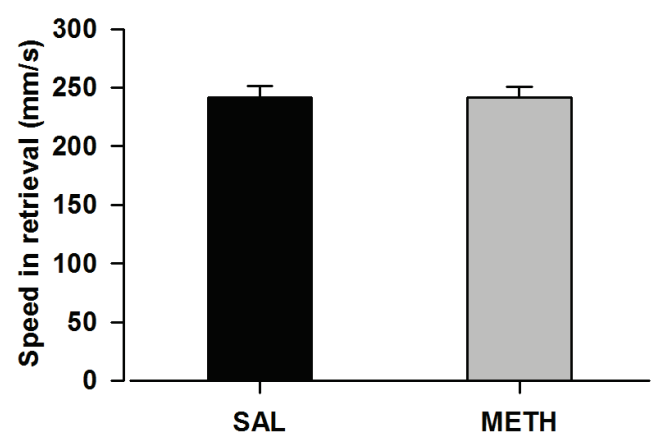

Fig. 3. Effects of acute METH exposure on working memory processes in mice. (A-B) The escape latencies in the acquisition trial and retrieval trial had no change between the saline group and acute METH exposure group. (C-D) Swimming speeds in the acquisition trial and retrieval trial. No difference in the working memory was observed between the saline group and acute METH exposure group. $n=11$ for per group, $\mathrm{P}>0.05$ vs. saline group.

A

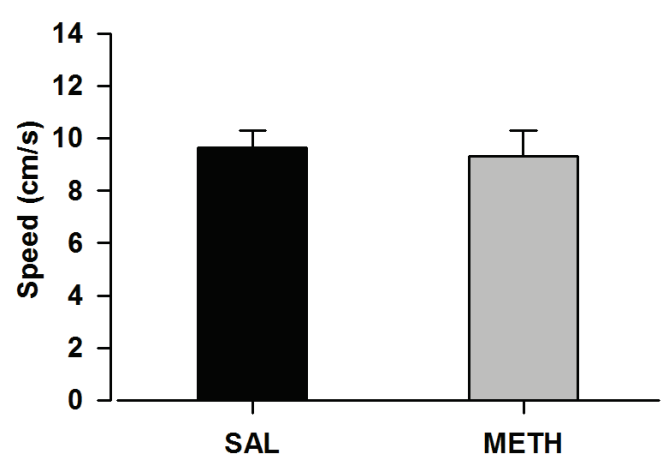

B

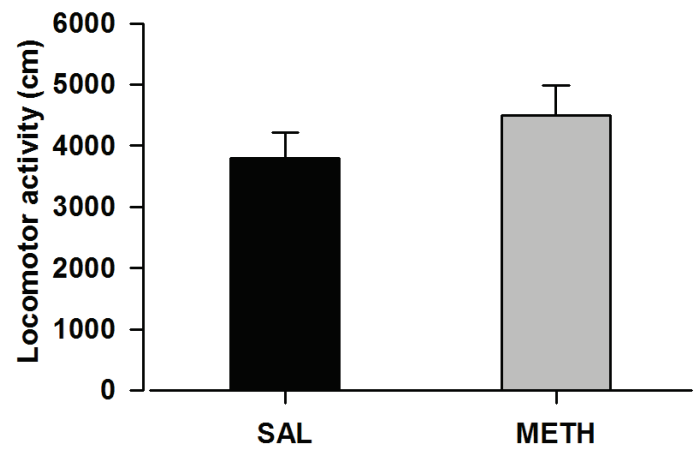

Fig. 4. Effects of acute METH exposure on locomotor activity in mice. (A) Speeds in the locomotor activity test. (B) Total distance of movements in locomotor activity test. The speed and total distance of movements in two groups exhibited no significant difference, which suggested that acute METH exposure did not affect the locomotion of mice. $n=6$ for per group, $P>0.05$ vs. saline group. 

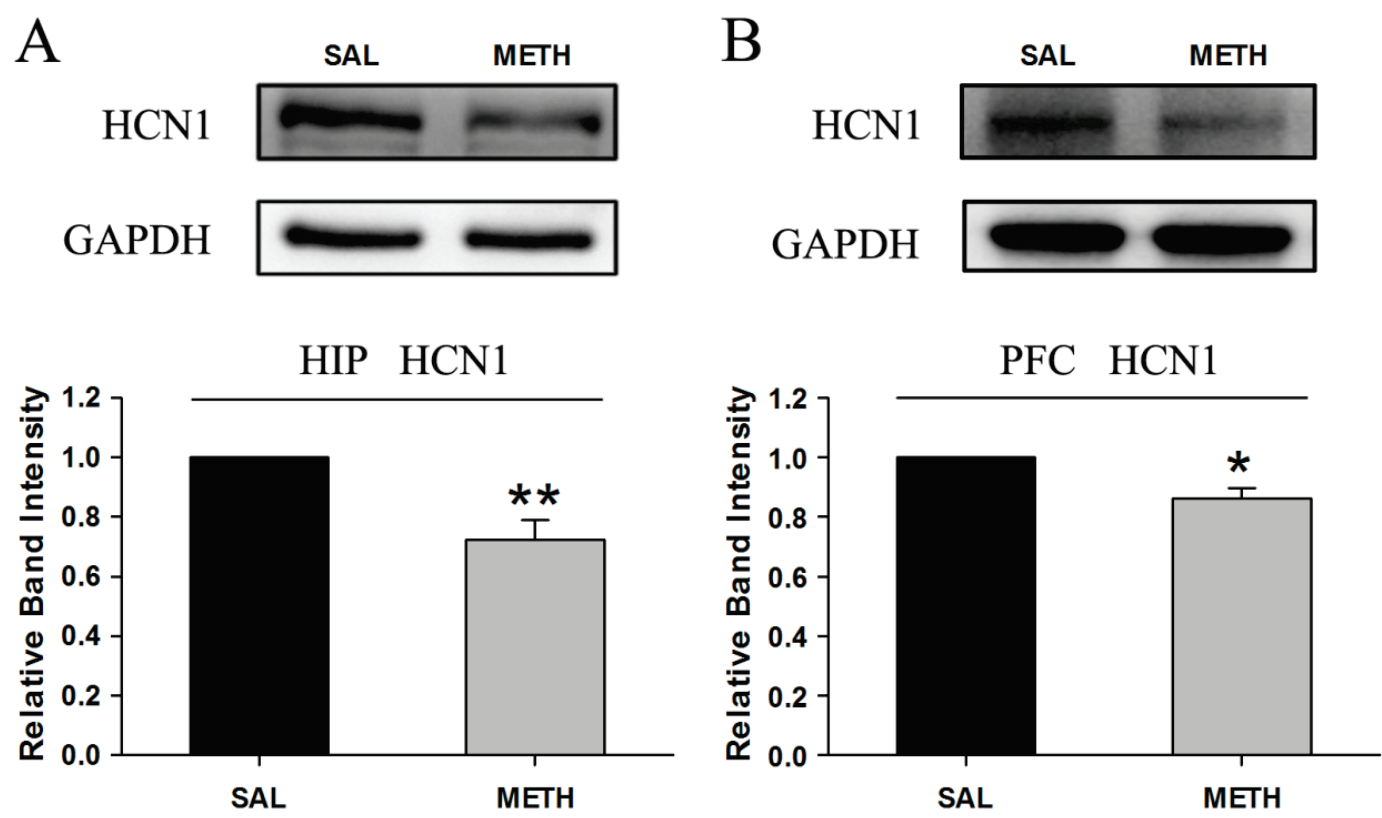

Fig. 5. Effects of METH re-exposure on the protein expression of HCN1 channels in mice HIP and PFC. (A) HCN1 channels protein level was markedly decreased in HIP of METH re-exposure mice. (B) The protein expression of HCN1 channels was also significantly reduced in PFC of METH re-exposure mice. $n=6$ for per group, $* \mathrm{P}<0.05$ and $* * \mathrm{P}<0.01$ vs. saline group.

HCN1 expression in HIP and PFC of mice with METH re-exposure

As illustrated in Figure 5A, the protein expression of $\mathrm{HCN} 1$ channels was significantly decreased in HIP of mice with METH re-exposure $(\mathrm{n}=6, \mathrm{P}<0.01)$. Meanwhile, HCN1 protein level was also significantly reduced in $\mathrm{PFC}$ of mice with METH re-exposure (Fig. 5B, $\mathrm{P}<0.05$ ).

Expression of p-ERK1/2/ERK1/2 in HIP and PFC of mice with METH re-exposure

The phosphorylated extracellular regulated protein kinase $1 / 2$ (p-ERK1/2) is thought to be responsible for the up-regulation of $\mathrm{HCN}$ channels. As shown in Figure 6, the p-ERK1/2 / ERK protein level was significantly decreased in both HIP and PFC of mice with METH re-exposure $(\mathrm{n}=6, \mathrm{P}<0.05)$, while the ERK1/2 protein level in two groups exhibited no significant difference $(\mathrm{P}>0.05)$.

Expression of HCN1 and p-ERK1/2/ERK1/2 in HIP and PFC of mice with acute METH exposure

The protein expression of HCN1 channels exhibited no significant difference in both HIP and PFC of mice with acute METH exposure (Fig. 7, n=6, $\mathrm{P}>0.05$ ). Meanwhile, no significant difference in p-ERK1/2 and ERK protein levels was observed in both HIP and PFC of mice with acute METH exposure (Fig. 8, $\mathrm{n}=6, \mathrm{P}>0.05$ ).

\section{Discussion}

METH is a highly addictive psychostimulant and the second most widely abused illicit drug in the world. Behavioral abnormalities induced by drug relapse were considered as a result of pathological changes in learning and memory, involving cell-signaling and synaptic mechanisms similar to those implicated in neural models of learning and memory (Hyman and Malenka 2001, Slamberova et al. 2014). In the present study, we found that METH re-exposure enhanced the working memory of mice, while acute METH exposure did not affect the working memory function. Our findings were similar to the observations from the clinical studies. It has been documented that low-dose METH administration improves attention and working memory in METHdependent individuals (Mahoney et al. 2011). Meanwhile, an oral administration of METH could also improve cognitive functions in healthy individuals (Silber et al. 2006). However, the molecular mechanism underlying memory dysfunctions caused by METH exposure was still unclear. This pathological enhancement of memory might serve as the underlying mechanism in the formation of behavioral abnormalities associated with drug relapse.

HCN channels conduct an inward, excitatory current $\mathrm{I}_{h}$ in the nervous system. Dysfunctions of HCN channels were involved in the neurological basis underlying several nervous system diseases, such as 
neuropathic pain, epilepsy, and Parkinson's disease (Lewis and Chetkovich 2011, Postea and Biel 2011). There was scarce information on the effect of METH on the expression of $\mathrm{HCN}$ channels in the brain. In the present study, we found that METH re-exposure reduced the protein expression of HCN1 channels in both HIP and PFC, while acute METH exposure did not affect the expression of HCN1 channels. Our finding was similar to the observation from González and colleagues, in which the withdrawal from repeated METH administration caused a significant decrease in HCN1 mRNA expression in PFC (Gonzalez et al. 2016). Therefore, we hypothesized that the down-regulation of $\mathrm{HCN} 1$ protein expression in both HIP and PFC areas might be a potential mechanism underlying the effect of METH re-exposure on memory functions.
A
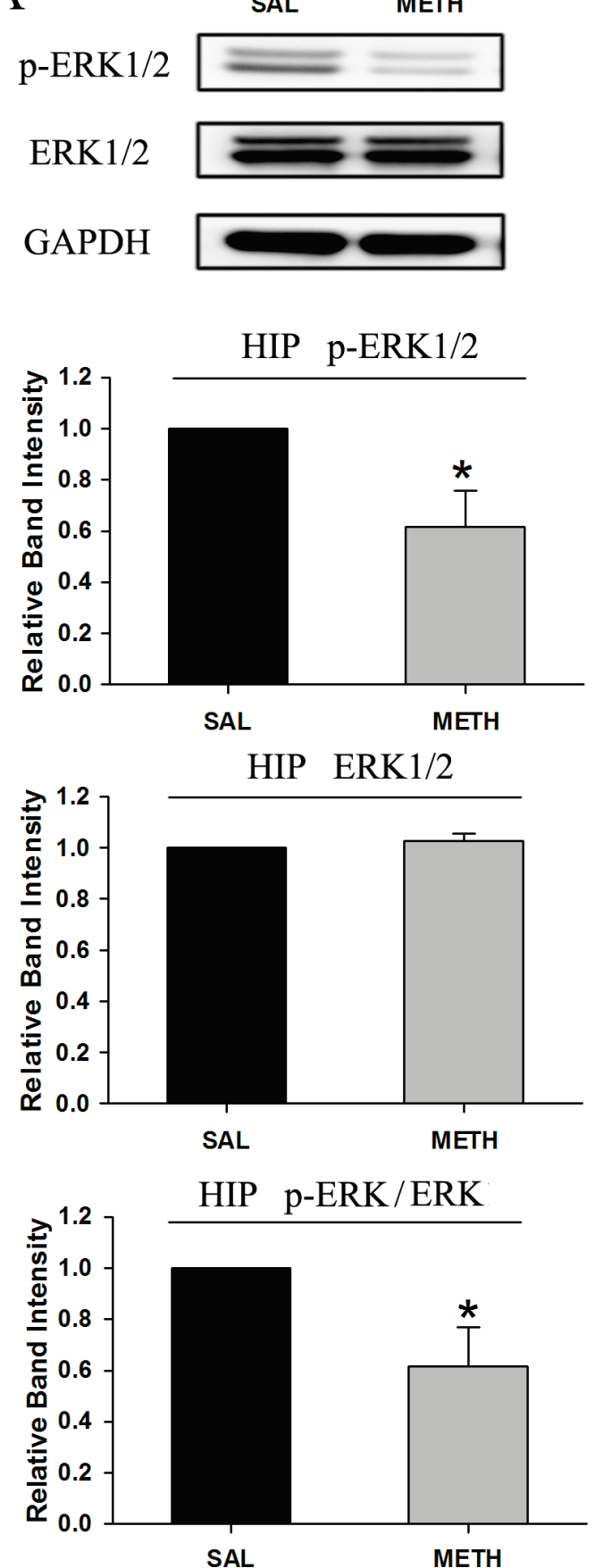

B
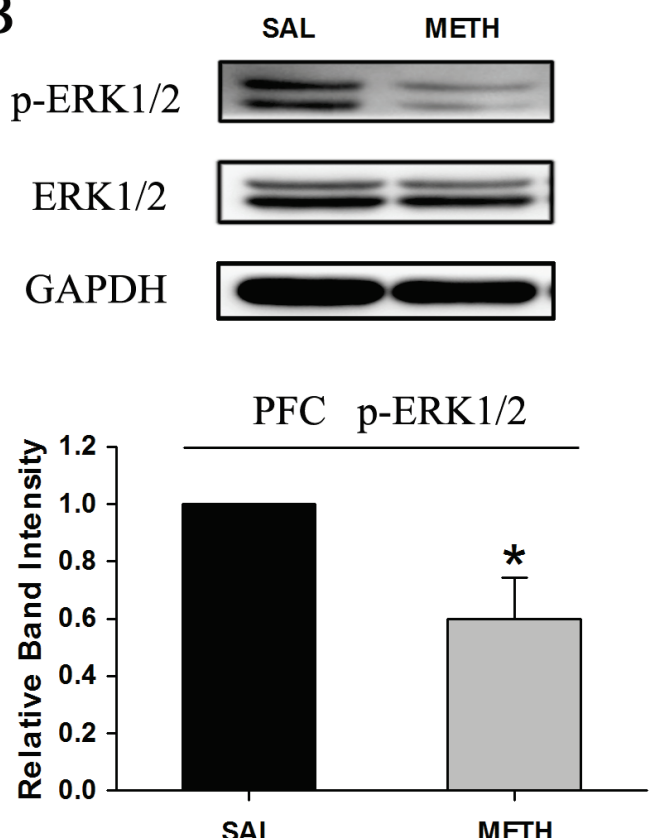

SAL

PFC ERK1/2
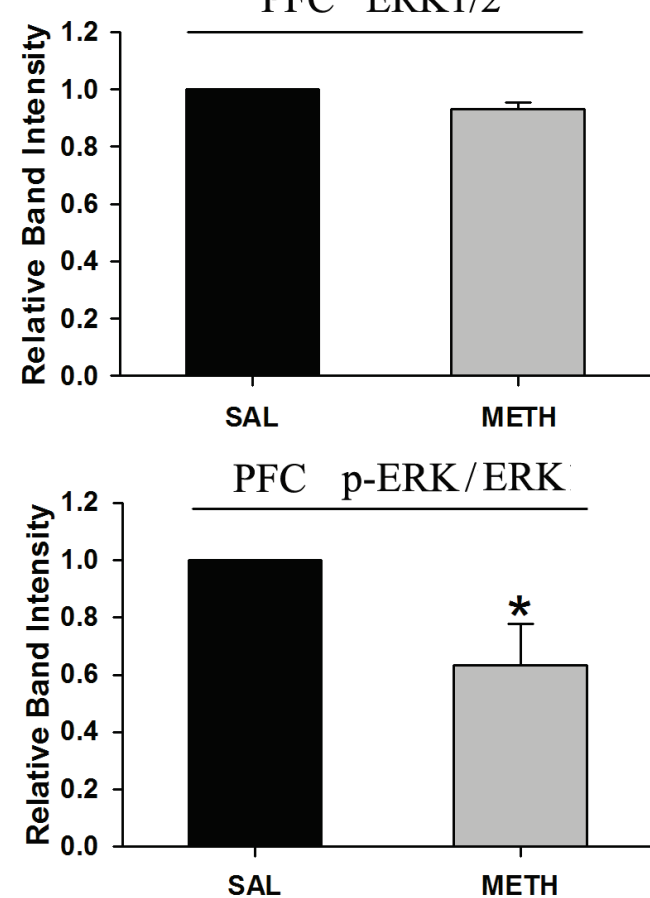

Fig. 6. Effects of METH re-exposure on the protein expression of $p$-ERK1/2/ERK1/2 in mice HIP and PFC. (A) $p$-ERK1/2/ERK1/2 protein level was significantly decreased in HIP of METH re-exposure mice. (B) The protein expression of p-ERK1/2/ERK1/2 was also markedly reduced in PFC of METH re-exposure mice. ERK1/2 protein level showed no significant difference between the saline group and METH re-exposure group in both HIP and PFC. $n=6$ for per group, $* \mathrm{P}<0.05$ vs. saline group. 
A

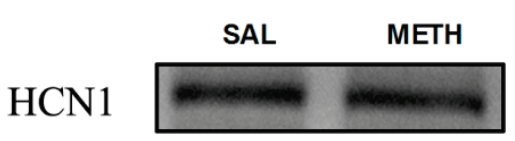

GAPDH

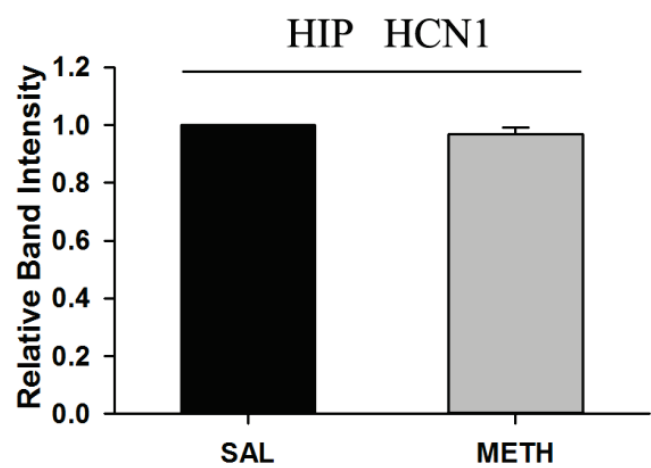

B

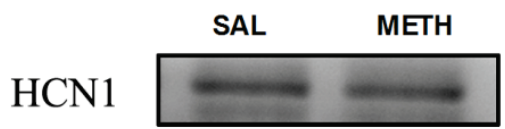

GAPDH
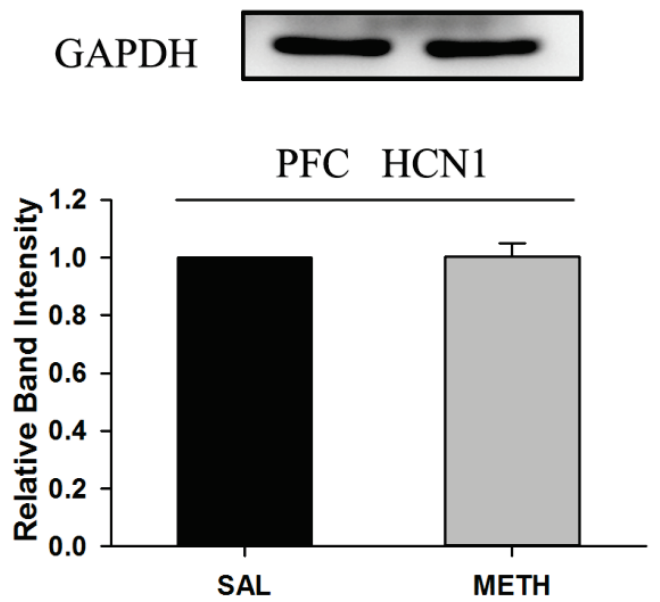

Fig. 7. Effects of acute METH exposure on the protein expression of HCN1 channels in mice HIP and PFC. (A) HCN1 channels protein level showed no significant difference between saline group and acute METH exposure group in HIP. (B) The protein expression of HCN1 channels exhibited no significant difference between saline group and acute METH exposure group in PFC. $n=6$ for per group, $\mathrm{P}>0.05$ vs. saline group.

Ample studies suggested that the alteration of HCN channels could regulate the synaptic plasticity, which was important for memory functions (Wang et al. 2011). HCN1 channels acted as an inhibitory constraint of both spatial learning and long-term plasticity in the distal dendrites of HIP by interfering with postsynaptic $\mathrm{Ca}^{2+}$ influx (Tsay et al. 2007). The deletion of forebrain HCN1 channels significantly enhanced the long-term potentiation amplitude in HIP, which caused increases in both short-term and long-term forms of spatial memory (Nolan et al. 2004). These studies suggested that alteration of HCN channels was associated with the neurological basis underlying memory functions. Based on the above findings, we hypothesized that the downregulation of $\mathrm{HCN} 1$ channels caused by METH re-exposure in the HIP and PFC might be related to pathological changes of the synaptic plasticity, which might be responsible for the enhancement of memory functions induced by METH re-exposure.

p-ERK1/2 played an important role in the regulation of several ion channels, such as Nav1.7 sodium channel (Stamboulian et al. 2010), which was also involved in the regulation of $\mathrm{HCN}$ channels. The pharmacological agonist of ERK1/2 signaling induced an enhanced effect on $\mathrm{I}_{\mathrm{h}}$ in guinea pig cardiac neuron (Tompkins et al. 2009). Moreover, the phosphorylation of ERK1/2 promoted the activation of filamin A (Zhao et al. 2016). Filamin $A$ was a specific regulator of $\mathrm{HCN} 1$ channels by interacting with the cyclic nucleotide-binding domain. The interaction of filamin A with HCN1 induced a significant up-regulation of $\mathrm{HCN} 1$ channels (Gravante et al. 2004). In our study, we found that p-ERK $1 / 2$ protein level was significantly decreased in both HIP and PFC of mice with METH re-exposure, while acute METH exposure did not affect the expression of p-ERK1/2. Some studies reported that METH treatment induced a decrease in ERK1/2 activity. Repeated $10 \mathrm{mg} / \mathrm{kg}$ METH treatment significantly reduced the total ERK1/2 expression in the PFC (Chen et al. 2012). Repeated $1 \mathrm{mg} / \mathrm{kg}$ METH treatment abolished the activation of ERK1/2 in the PFC in saline-treated mice after exposure to novel objects (Mizoguchi et al. 2008). Based on the role of ERK1/2 in the regulation of $\mathrm{HCN}$ channels, these findings suggested that $\mathrm{p}$-ERK1/2 might be involved in the reduction of $\mathrm{HCN} 1$ protein expression of mice with METH re-exposure.

\section{Conclusions}

METH abuse is a complex neuropsychiatric disorder that has been taken as a result of pathological changes in memory. Our results demonstrated the novel information that METH re-exposure reduced the protein expression of HCN1 channels in both HIP and PFC area, which might due to the decreased protein level of p-ERK1/2. Since the important role of HCN channels in 
A

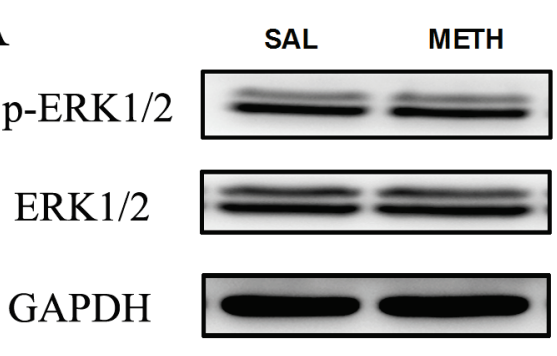

HIP p-ERK $1 / 2$

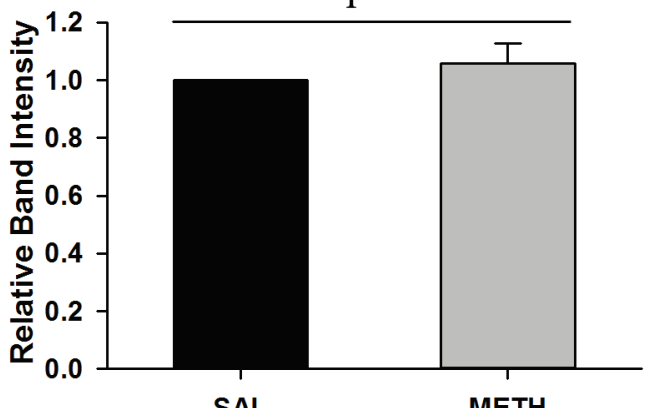

SAL
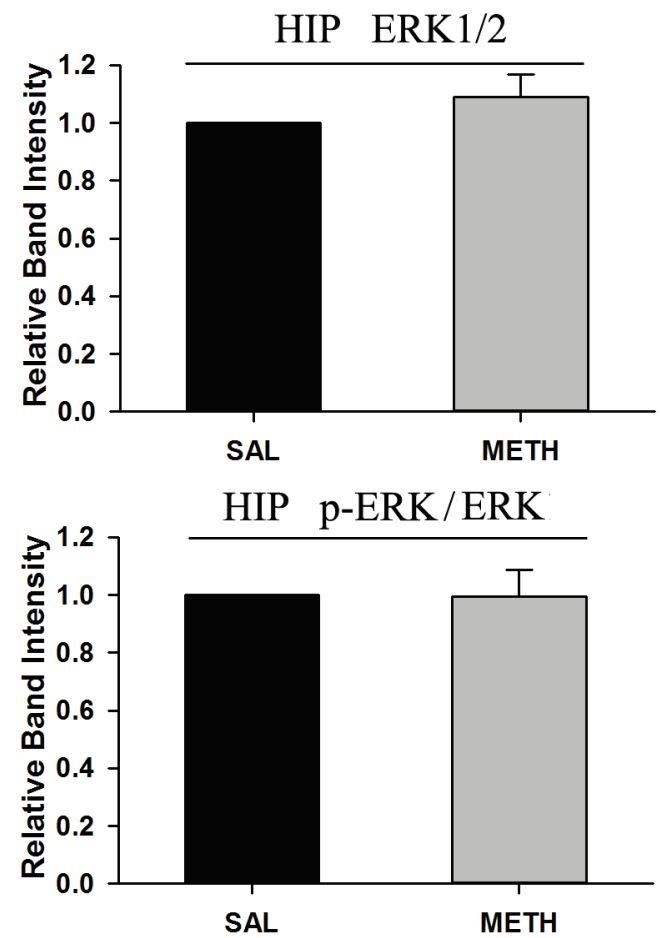

B
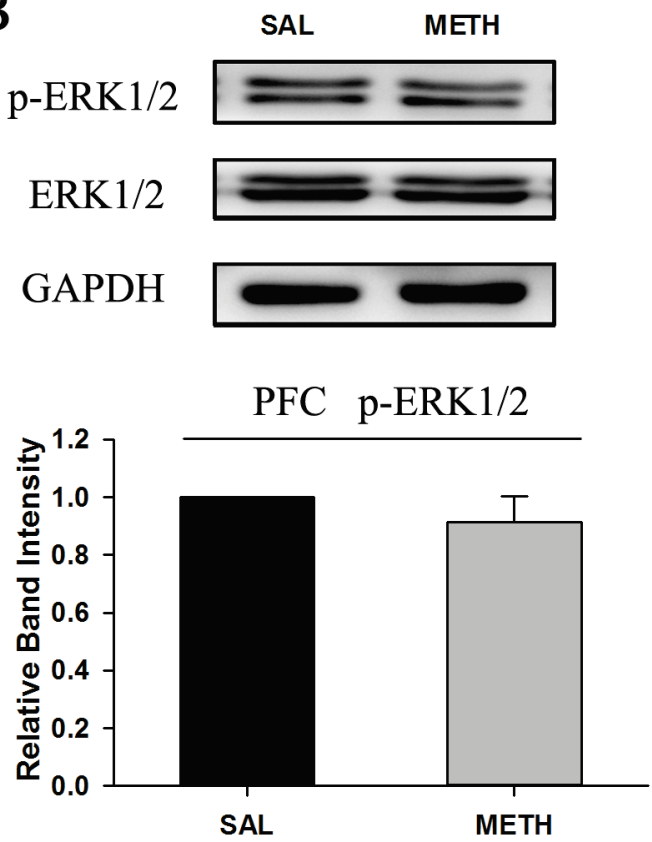

PFC ERK $1 / 2$

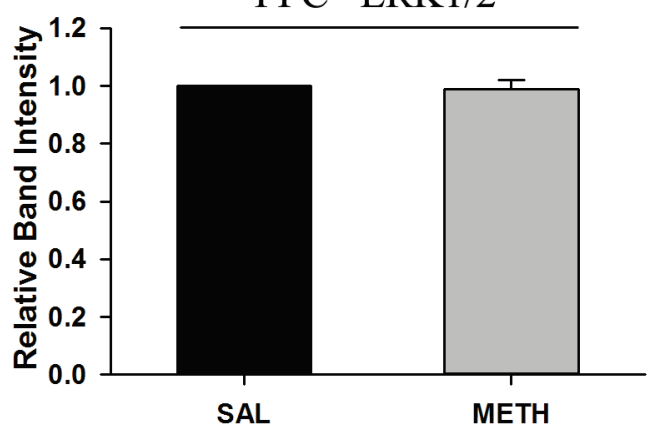

PFC p-ERK/ERK

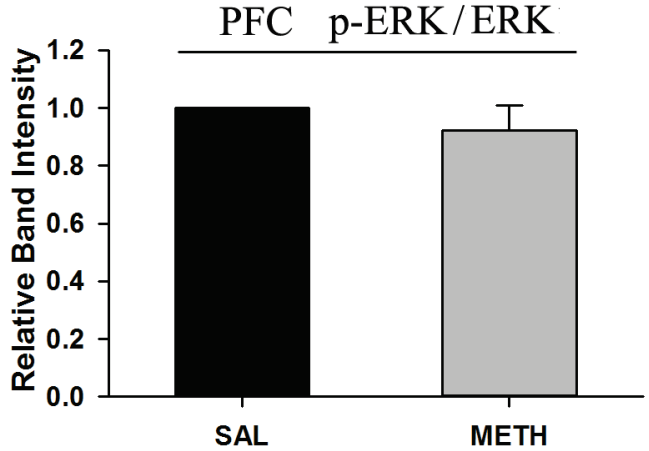

Fig. 8. Effects of acute METH exposure on the protein expression of $p$-ERK1/2/ERK $1 / 2$ in mice HIP and PFC. (A) The protein expressions of $p$-ERK1/2 and ERK1/2 exhibited no significant difference between the saline group and acute METH exposure group in HIP. (B) There was no significant change in $p$-ERK1/2 and ERK protein levels in PFC of mice with acute METH exposure. $n=6$ for per group, $\mathrm{P}>0.05$ vs. saline group.

the regulation of memory function, the down-regulation of HCN1 expression might account for enhanced working memory induced by METH re-exposure. Taken together, our findings suggested that the down-regulation of HCN1 channels might be the neurobiological basis underlying the pathological alteration of memory functions that occurred in METH re-exposure.

\section{Conflict of Interest}

There is no conflict of interest.

\section{Acknowledgements}

This work was supported by grants from the Science and Technology Research Project of Hubei Provincial Department of Education (No. B2016294). 


\section{Abbreviations}

ERK, extracellular regulated protein kinases; $\mathrm{HCN}$ channels, hyperpolarization-activated cyclic-nucleotide- gated non-selective cation channels; HIP, hippocampus; METH, methamphetamine; MWM, Morris water maze; PFC, prefrontal cortex; VTA, ventral tegmental area.

\section{References}

ARENCIBIA-ALBITE F, VAZQUEZ R, VELASQUEZ-MARTINEZ MC, JIMENEZ-RIVERA CA: Cocaine sensitization inhibits the hyperpolarization-activated cation current $\mathrm{Ih}$ and reduces cell size in dopamine neurons of the ventral tegmental area. J Neurophysiol 107: 2271-2282, 2012.

BENARROCH EE: HCN channels: function and clinical implications. Neurology 80: 304-310, 2013.

BIEL M, WAHL-SCHOTT C, MICHALAKIS S, ZONG X: Hyperpolarization-activated cation channels: from genes to function. Physiol Rev 89: 847-885, 2009.

BRAREN SH, DRAPALA D, TULLOCH IK, SERRANO PA: Methamphetamine-induced short-term increase and long-term decrease in spatial working memory affects protein Kinase M zeta (PKMzeta), dopamine, and glutamate receptors. Front Behav Neurosci 8: 438, 2014.

CAO G, ZHU J, ZHONG Q, SHI C, DANG Y, HAN W, LIU X, XU M, CHEN T: Distinct roles of methamphetamine in modulating spatial memory consolidation, retrieval, reconsolidation and the accompanying changes of ERK and CREB activation in hippocampus and prefrontal cortex. Neuropharmacology 67: 144-154, 2013.

CHEN YJ, LIU YL, ZHONG Q, YU YF, SU HL, TOQUE HA, DANG YH, CHEN F, XU M, CHEN T: Tetrahydropalmatine protects against methamphetamine-induced spatial learning and memory impairment in mice. Neurosci Bull 28: 222-232, 2012.

GONZALEZ B, RIVERO-ECHETO C, MUNIZ JA, CADET JL, GARCIA-RILL E, URBANO FJ, BISAGNO V: Methamphetamine blunts $\mathrm{Ca}(2+)$ currents and excitatory synaptic transmission through $\mathrm{D} 1 / 5$ receptormediated mechanisms in the mouse medial prefrontal cortex. Addict Biol 21: 589-602, 2016.

GRAVANTE B, BARBUTI A, MILANESI R, ZAPPI I, VISCOMI C, DIFRANCESCO D: Interaction of the pacemaker channel HCN1 with filamin A. J Biol Chem 279: 43847-43853, 2004.

HENDERSHOT CS, WITKIEWITZ K, GEORGE WH, MARLATT GA: Relapse prevention for addictive behaviors. Subst Abuse Treat Prev Policy 6: 17, 2011.

HOPF FW, MARTIN M, CHEN BT, BOWERS MS, MOHAMEDI MM, BONCI A: Withdrawal from intermittent ethanol exposure increases probability of burst firing in VTA neurons in vitro. $J$ Neurophysiol 98: 2297-2310, 2007.

HYMAN SE: Addiction: a disease of learning and memory. Am J Psychiatry 162: 1414-1422, 2005.

HYMAN SE, MALENKA RC: Addiction and the brain: the neurobiology of compulsion and its persistence. Nat Rev Neurosci 2: 695-703, 2001.

LEWIS AS, CHETKOVICH DM: HCN channels in behavior and neurological disease: too hyper or not active enough? Mol Cell Neurosci 46: 357-367, 2011.

MACUCHOVA E, NOHEJLOVA-DEYKUN K, SLAMBEROVA R: Effect of methamphetamine on cognitive functions of adult female rats prenatally exposed to the same drug. Physiol Res 62 (Suppl 1): S89-S98, 2013.

MAHONEY JJ 3RD, JACKSON BJ, KALECHSTEIN AD, DE LA GARZA R 2ND, NEWTON TF: Acute, low-dose methamphetamine administration improves attention/information processing speed and working memory in methamphetamine-dependent individuals displaying poorer cognitive performance at baseline. Prog Neuropsychopharmacol Biol Psychiatry 35: 459-465, 2011.

MILADI GORJI H, RASHIDY-POUR A, FATHOLLAHI Y: Effects of morphine dependence on the performance of rats in reference and working versions of the water maze. Physiol Behav 93: 622-627, 2008.

MIZOGUCHI H, TAKUMA K, FUKAKUSA A, ITO Y, NAKATANI A, IBI D, KIM HC, YAMADA K: Improvement by minocycline of methamphetamine-induced impairment of recognition memory in mice. Psychopharmacology (Berl) 196: 233-241, 2008. 
NOLAN MF, MALLERET G, DUDMAN JT, BUHL DL, SANTORO B, GIBBS E, VRONSKAYA S, BUZSAKI G, SIEGELBAUM SA, KANDEL ER, MOROZOV A: A behavioral role for dendritic integration: HCN1 channels constrain spatial memory and plasticity at inputs to distal dendrites of CA1 pyramidal neurons. Cell 119: 719-732, 2004.

NOTOMI T, SHIGEMOTO R: Immunohistochemical localization of Ih channel subunits, HCN1-4, in the rat brain. J Comp Neurol 471: 241-276, 2004.

OKAMOTO T, HARNETT MT, MORIKAWA H: Hyperpolarization-activated cation current (Ih) is an ethanol target in midbrain dopamine neurons of mice. J Neurophysiol 95: 619-626, 2006.

POSTEA O, BIEL M: Exploring HCN channels as novel drug targets. Nat Rev Drug Discov 10: 903-914, 2011.

RAU TF, KOTHIWAL AS, ROVA AR, BROOKS DM, RHODERICK JF, POULSEN AJ, HUTCHINSON J, POULSEN DJ: Administration of low dose methamphetamine $12 \mathrm{~h}$ after a severe traumatic brain injury prevents neurological dysfunction and cognitive impairment in rats. Exp Neurol 253: 31-40, 2014.

SCHUTOVA B, HRUBA L, POMETLOVA M, DEYKUN K, SLAMBEROVA R: Cognitive functions and drug sensitivity in adult male rats prenatally exposed to methamphetamine. Physiol Res 58: 741-750, 2009.

SILBER BY, CROFT RJ, PAPAFOTIOU K, STOUGH C: The acute effects of d-amphetamine and methamphetamine on attention and psychomotor performance. Psychopharmacology (Berl) 187: 154-169, 2006.

SLAMBEROVA R, VRAJOVA M, SCHUTOVA B, MERTLOVA M, MACUCHOVA E, NOHEJLOVA K, HRUBA L, PUSKARCIKOVA J, BUBENIKOVA-VALESOVA V, YAMAMOTOVA A: Prenatal methamphetamine exposure induces long-lasting alterations in memory and development of NMDA receptors in the hippocampus. Physiol Res 63 (Suppl 4): S547-S558, 2014.

STAMBOULIAN S, CHOI JS, AHN HS, CHANG YW, TYRRELL L, BLACK JA, WAXMAN SG, DIB-HAJJ SD: ERK1/2 mitogen-activated protein kinase phosphorylates sodium channel $\mathrm{Na}(\mathrm{v}) 1.7$ and alters its gating properties. J Neurosci 30: 1637-1647, 2010.

TOMPKINS JD, LAWRENCE YT, PARSONS RL: Enhancement of Ih, but not inhibition of IM, is a key mechanism underlying the PACAP-induced increase in excitability of guinea pig intrinsic cardiac neurons. Am J Physiol Regul Integr Comp Physiol 297: R52-R59, 2009.

TSAY D, DUDMAN JT, SIEGELBAUM SA: HCN1 channels constrain synaptically evoked Ca2+ spikes in distal dendrites of CA1 pyramidal neurons. Neuron 56: 1076-1089, 2007.

WANG M, GAMO NJ, YANG Y, JIN LE, WANG XJ, LAUBACH M, MAZER JA, LEE D, ARNSTEN AF: Neuronal basis of age-related working memory decline. Nature 476: 210-213, 2011.

ZHAO P, MA W, HU Z, ZANG L, TIAN Z, ZHANG K: Filamin A (FLNA) modulates chemosensitivity to docetaxel in triple-negative breast cancer through the MAPK/ERK pathway. Tumour Biol 37: 5107-5115, 2016. 